\title{
EL IMPUESTO TERRITORIAL
}

\begin{abstract}
"A cada uno toca examinar su conciencia, que tiene una nueva voz para nuestra época. ¿Está dispuesto a sostener con su dinero las obras y las empresas organizadas en favor de los más pobres? ¿A pagar más impuestos para que los poderes públicos intensifiquen su esfuerzo para el desarrollo?

El mundo está enfermo. Su mal está menos en la esterilización de los recursos y en su acaparamiento por parte de algunos, que en la falta de fraternidad entre los hombres y entre los pueblos. No basta aumentar la riqueza común para que sea repartida equitativamente. Se trata de construir un mundo donde todo hombre, sin excepción de raza, religión o nacionalidad, pueda vivir una vida plenamente humana..."
\end{abstract}

\section{CONSIDERACIONES GENERALES}

La razón de haber encabezado este artículo de orden tributario, con conceptos económico-sociales extraidos de la célebre Encíclica sobre el desarrollo de los pueblos que dirigiera el Papa Paulo VI a los hombres de buena voluntad, obedece a la afinidad de los mismos con las nuevas metas fundamentales de la Política Financiera (1).

De otra parte, se debe a que en la actualidad se considera que los fines extrafiscales de los impuestos, o sea los sociales, políticos y económicos son tanto o más valiosos que los fiscales, y que ellos son suficientes para justificar en determinados casos, según la estructura económica de un país, el establecimiento de nuevos tributos. Es decir que la finalidad de la tributación ya no es más sólo el "servicio público", sino que dicho concepto ha sido superado por el de "bien común", como acertadamente señala el Dr. Juan Lino Castillo en su valioso trabajo "Tributación y Derecho" (2).

En consecuencia, en un estudio sobre la creación del Impuesto Territorial en el Perú, debe contemplarse francamente no sólo su condición de nuevo recurso fiscal, sino su trascendencia social-económica, pues el mismo

1 Heinz Haller Política Financiera.

2 Conferencia dictada en el Colegio de Abogados de Lima -24 de junio de 1965-Editorial Studium - Pág. 6. se podria exigir a los contribuyentes no sólo en razón de la capacidad tributaria que revela la condición de propietario, sino, además, como un sacrificio en aras de la fraternidad humana - justicia social-, valor que supera la barrera de la conveniencia económica inmediata.

El Impuesto Territorial es uno de los tributos que claramente puede considerarse en la situación especial de responder a fines extrafiscales de orden social. El afecta una riqueza visible que permanentemente ha sido considerada como una fuente impositiva de primer orden.

En nuestro concepto, al margen de la signiíicación del Impuesto Territorial como ingreso fiscal, su existencia se justifica juridica y económicamente, en cuanto grava una capacidad tributaria manifiesta. Socialmente, en cuanto puede ser utilizado como instrumento de reforma agraria.

De ahi que nos declaremos partidarios de la implantación de este tributo; pero, eso sí, dentro de un sistema tributario distinto al actual. Vale decir, que el $\mathrm{Im}$ puesto Territorial no debe agregarse simplemente a los impuestos vigentes, aumentando así el caos fiscal que sufrimos, sino que dentro del replanteamiento total impositivo que el país exige se considere dentro de un sistema orgánico de impuestos que graven la propiedad inmueble e involucre todos los existentes, tales como el Impuesto a los Predios, el Impuesto a los Terrenos 
sin Construir, los Arbitrios de Alumbrado, Parques y Jardines, etc. Es decir, que deben integrarse debidamente modificados dentro de un solo tributo, concebido de tal modo que la carga total impositiva que represente no desaliente la inversión inmobiliaria, esté realmente de acuerdo con la capacidad tributaria de los contribuyentes, el rendimiento efectivo de los bienes y abarque los diversos hechos imponibles que presenta la propiedad, su disfrute y explotación (3).

Por ello, esia posicićn de amparo al Impuesto Territorial no significa una renuncia a la tesis general que defendemos, consistente en que en el Perú, lo que se requiere para resolver el problema crónico de mayores ingresos fiscales es básicamente una restructuración tributaria que a través de una imposición justa y técnica (tarifa de impuestos adecuada al actual poder adquisitivo de la moneda, y un sistema tributario en armonia con la capacidad contributiva de los obligados y nuestra realidad nacional socio-económica-geográfica) permita su cumplimiento cabal, evite la evasión y contemple el reparto equitativo de la presión fiscal.

En los últimos tres años se ha venido discutiendo en el pais el establecimiento del Impuesto Territorial. Los opositores a su creación han logrado detener los proyectos presentados que adolecian de graves de:ectos.

Sin embargo, tal como hemos dicho, creemos que ante la búsqueda constante de nuevas fuentes de recursos fiscales para satisfacer las crecientes necesidades del Estado y dadas las razones legales, sociales y económicas que los justifican, no puede dejarse de considerar la posibilidad de su implantación. Pero, dentro de un proceso de reforma tributaria total.

Por ello resulta importante recordar los aspectos generales de este impuesto en relación con los que presentan los proyectos peruanos. Adem ́s, conviene señalar como premisa básica que para su vigencia y éxito, necesaria y paralelamente debe crearse una "conciencia tributaria". Sólo ésta puede llevar al cumplimienio de las obligaciones fiscales y la aceptación de cargas impositivas motivadas especialmente por consideraciones de orden social.

Asimismo debe tenerse presente que el Estado no recuperará su autoridad moral para demandar el respeto a la ley, mientras no cumpla con restructurar un sistema tributario justo y varíe su conducta inmoral e ilegal.

No debe olvidarse que la subsistencia del rompecabezas fiscal vigente y la inseguridad jurídica son los prin-

3 Exposición de Motivos del Proyecto de Presupuesto Funcional para 1965 - Pags. 19, 28 y 30. cipales factores negativos que han contribuido a la existencia de esta "suerte de privilegio" de no pagar impuestos. "Suerte de privilegio" que puede traducirse como la autorización indirecta al incumplimiento de los deberas tributarios. Autorización que tiene su origen en las dos condiciones negativas referidas y que llevan a los contribuyentes a defraudar al Fisco.

Esta conducta y actitud de "tratar de no pagar impuestos" obedece además al desquite que toman los contribuyentes por el incumplimiento que hace constantemente el propio Estado del Código Tributario y otras normas legales en forma arbitraria e impune, por su permanenie voracidad, por la dilapidación de los caudales públicos, el abuso de autoridad, la existencia inconstitucional de privilegios personales irritantes $\in n$ materia de impuestos y el cobro de intereses usurarios, entre otras causas.

\section{DESARROLLO HISTORICO}

\section{1 General:}

El Impuesto Territorial está reputado como uno de los tributos más antiguos y sin duda el que fuera más imporiante. A estos méritos une el hecho de no haber sido abandonado hasta el presente pese a l:s variantes de legislacićn, más en la forma que en la esencia.

Esta imposición nació prácticamente al mismo tiempo que se fue determinando y consagrando el derecho de dominio $\mathrm{y} / \mathrm{o}$ el de disfrute $o$ posesión de las tierras.

Orgiinalmente gravó sólo la propiedad rústica, pero la expansión de las ciudades dio lugar a que se incluyera también a los predios urbanos como objeto de imposición. El Impuesto Territorial ha recibido diversas denominaciones durante su vida.

Las principales han sido las siguientes: Impuesto a las Tierras, Contribución Territorial, Impuesto a la Propiedad, Impuesto a las Edificaciones, Impuesto Predial e incluso Impuesto al Patrimonio.

Se ha señalado con acierto que existe relación necesaria entre la estructura económica de un país y su estructura tributaria (4). Igual hecho sucede con los períodos históricos.

Investigadores de tiempos remotos como Herodoto y Gastón Maspero, cada uno en su época, se refieren a la presencia de este gravamen en Babilonia, Egipto y Cal-

4 Hubert Brochier Finances Publiques ct Redestribution des Revenus. Cita hecha por el Dr. Juan Lino Castillo, obra citada, pág. 2. 
dea, pais este último donde existia un catastro que permitía establecer sobre bases sólidas el impuesto y calcular su rendimiento (5).

En las monarquías absolutas de Babilonia y Egipto, las necesidades financieras contribuyeron a que la administración fiscal ocupara lugar de privilegio en la organización estatal. Contaban con un cuerpo de funcionarios expertos que sirviéndose de los recursos de la contabilidad, el catastro y el registro fiscal, determinaban exactamente las obligaciones tributarias de cada súbdito.

En Grecia, las técnicas recaudatorias no fueron inicialmente tan avanzadas. Los ingresos del Estado en los primeros tiempos procedian de las tierras del Rey. Con la expansión de los gastos estatales la situación varió.

La política financiera del Imperio Romano se caracterizó al comienzo por la explotación fiscal de los nuevos territorios conquistados. Diocleciano fue el que creó el sistema tributario basado en el impuesto sobre la tierra. La tributación fue conocida como el vectigal certum. Su imposición respondia al principio de que la propiedad inmobiliaria era el fundus optimus maximus. Sin embargo, dada la fuerte imposición que recaía sobre las tierras, pues sólo se contemplaban tarifas fijas sin tener en cuenta los resultados de las cosechas, los campesinos cayeron en grandes deudas impositivas y abandonaron los campos.

Esta influencia fiscal romana se extendió también al Segundo Imperio Persa, en el que los sasánidas crearon un Estado asiático bien organizado tributariamente. El elemento central del sistema fue el impuesto sobre las tierras, previa medición de los predios, y con tarlfas graduadas sobre las distintas clases de cultivo.

En la Edad Media los sistemas tributarios guardaron armonía con el desarrollo del feudalismo, el fortalecimiento del poder de las ciudades y de los príncipes te. rritoriales. El impuesto a las tierras, considerado como un recorte a la libertad, contó con la resistencia de los obligados. Ello se vio agravado por la falta de organización administrativa adecuada para su recaudación. Sólo cuando el Rey era también señor territorial podía obtener ingresos con cierta regularidad.

En ese período los contribuyentes más destacados fueron las florecientes ciudades imperiales. Sus pagos extraordinarios y obligatorios constituyeron en sentido

5 Günter Schmölders Teoría General del Impuesto - Editorial de Derecho Financiero - Madrid, 1962, Pág. 5. estricto el punto de arranque del Impuesto Territorial, el cual recibió el nombre de "bede" (pedido) y gravaba la propiedad de tierras y edificios. Su nombre provenia del hecho de la petición de la concesión de impuestos del Rey, tanto a los señores como a las ciudades.

Este impuesto, durante esa época, fue llamado también "schors" en el Sacro Imperio Alemán y en otros reinos "Contribución al Tesoro".

En el Siglo XII los príncipes territoriales comenzaron también por su parte, bajo el mismo nombre de "bede", a recaudar impuestos. Estos gravaban principalmente la propiedad territorial y eran los gobiernos locales o municipios los responsables de su recaudación.

Los impuestos sobre la tierra no constituyeron en esa época un ingreso regular, sino ayudas especiales para gastos extraordinarios, tales como guerras, rescates, matrimonios, etc.

La Edad Moderna trajo el perfeccionamiento de la hacienda. Resultado de ello fue la existencia de catastros más completos y ajustados, así como la tecnificación de los impuestos.

El Impuesto Territorial que venia considerando como única materia gravable la simple posesión o dominio inmobiliario, dado el valor que significaba su disfrute 0 su uso en la producción, amplió su esfera de acción a los resultados mismos de la explotación del predio, o sea a los beneficios, que hoy precisamente son objeto de los Impuestos a la Renta, en casi todos los países.

Posteriormente, a mediados del siglo pasado, recién comenzaron a producirse los cambios fiscales que dieron lugar a los impuestos que subsisten hasta nuestros días.

Inglaterra fue la primera en iniciar la tendencia orientada al desplazamiento de la exacción (land-tax), cobrando el impuesto exclusivamente sobre la renta y ya no sobre la propiedad raíz en su condición de riqueza determinada según su valuación. En cambio, en otros países como en Francia, Estados Unidos, Nueva Zelandia, etc., sin perjuicio de dar un tratamiento tributario distinto a los resultados de la explotación predial dentro de sus Impuestos a la Renta, se ha conservado también el gravamen directo al valor del suelo, manteniendo hasta hoy esta imposición, aunque con nuevas modalidades.

Hoy la contribución territorial ha seguido formando parte de los regímenes tributarios de casi todos los paises, tales como Japón, Italia, Suiza, Estados Unidos, Francia, España, Argentina, Nueva Zelandia, etc. 


\section{2 En el Perú}

El Impuesto Territorial tiene como antecedente más remoto las contribuciones en especie o trabajo.

En el Perú antiguo, el principal tributo que se pagaba al Inca era el labrar y beneficiar las tierras del Sol y del Inca y coger los frutos, cualesquiera que fuesen, y encerrarlos en sus horones y ponerlos en los depósitos reales que había en cada pueblo para recoger los frutos (6).

El Padre Acosta consigna el hecho de que el tributo que habia de pagarse en épocas del Imperio Incaico "era labrar y beneficiar las tierras del Inca y poner en sus depósitos los frutos" (7).

Louis Baudin señala que los Incas establecieron un sistema de tributo casi perfecto, gracias a la estadistica. Que el tributo consistia en el trabajo personal, pues no se establecía directamente ningún gravamen sobre los bienes de propiedad del contribuyente, ni sobre los productos del "tupu". El principal tributo consistía en el cultivo de las tierras del Sol y del Inca (8).

"El trauma de la conquista trastrocó la organización económica, política y social de los Incas, subsistiendo el sistema de tenencia y explotación del agro - base de la vida incaica - y relegando la agricultura a un segundo plano, para polarizar el trabajo en el laboreo de las minas". "Consumada la conquista, el indio quedó obligado al pago del tributo" (9). Todos debían pagar diezmos y primicias. Tributaban en especie, pagando con los frutos que obtenían de su trabajo, principalmente agrícola.

Durante el virreinato, el régimen tributario tuvo como base el sistema de "capitación", o sea el pago de impuestos por cabeza.

En relación con la propiedad los principales fueron: la "alcabala" que se cobraba por la transferencia de bienes con la tasa del 2\%; "juro" que era un tributo que gravaba el derecho de propiedad; el "medio diezmo civil", impuesto que debian satisfacer los agricultores de la costa; "peches", imposición en especie que se paga-

6 Garcilaso de la Vega Comentarios Reales, Libro V, Cap. V, Cita hecha por Antenor del Pozo y Alfredo S. García G. Impuestos en el Perú.

7 Idem, pág. 8.

8 Luis Baudin El Imperio Socialista de los Incas, Edit. Zig Zag, Pág. 297.

9 Garcilaso de la Vega Comentarios Reales, Libro V, Cap. V, Cita hecha por Antenor del Pozo y Alfredo S. García G. Impuestos en el Perú. ba mediante la entrega de productos agrícolas, aves, ganado y otros bienes similares, y "esto sin tener en cuenta que debian cultivarle gratuitamente sus tierras a los principales" (10); "composición de tierras", tributo que tuvo su origen en la cédula de $1^{\circ}$ de noviembre de 1591, y en el cual se autorizó al Virrey para que con el objeto de incrementar las entradas de la real hacienda, se hiciera pagar el valor de las tierras a españoles y naturales que disfrutaban de la posesión de tierras, sin tener justo y legítimo título de propiedad sobre ellas (11).

Con la emancipación y la república varió el sistema tributario.

El año de 1825 nació el impuesto a los predios rústicos y urbanos, a través del cual no se gravó la propiedad sino sus frutos con una tasa del $5 \%$ que después se redujo al 3\%. Este tributo se modificó en 1826 estableciéndose sobre los arrendamientos.

En 1832 se rebajaron los diezmos autorizándose a deducir los gastos de cultivo de los productos agrícolas.

Al producirse, en época de Santa Cruz, la guerra con Chile, hubo un intento de introducir una nueva ley de impuesto predial que no llegó a prosperar.

El Presidente Castilla modificó totalmente el régimen tributario. Suprimió el sistema de capitación y otras contribuciones personales. Por Decreto Dictatorial de 26 de julio de 1855 estableció diversos impuestos directos, entre ellos el impuesto a los predios urbanos y rústicos. En esta imposición se consideró como única materia gravable las rentas líquidas y los arrendamientos. La tarifa del impuesto fue del $4 \%$ al año.

La ley de 23 de agosto de 1892 varió el impuesto predial. Introdujo la posibilidad de deducir de la renta bruta estimada o de arrendamientos un porcentaje del $20 \%$. En el caso de fundos agrícolas se autorizó a deducir además los gastos de cultivo; y, tratándose de inmuebles de empleados en actividades de lucro, un porcentaje del $25 \%$ en lugar de $20 \%$.

Posteriormente, por Decreto Supremo de 20 de abril de 1906, se creó un registro predial o sistema de catastro. Se diferenció los predios urbanos de los rústicos. Los primeros fueron agrupados por distritos y calles. Los segundos por distritos y valles.

Mediante la ley 2592 del $1^{\circ}$ de diciembre de 1917 se creó un impuesto al valor de la propiedad, acotable únicamente a los terrenos sin construir.

10 Idem, Págs. 17 y 18.

11 Idem, Pág. 383. 
Finalmente, en 1934, se dio la ley general № 7904 de Impuestos a la Renta que entró en vigencia en 1936.

Dicha ley estableció un sistema de impuestos cedulares, así llamados porque cada uno de ellos grava una renta clasificada según su origen (de bienes inmuebles, de capital y trabajo, de trabajo sólo, de capital movible) y a los cuales se agrega un impuesto global relacionado con la capacidad de pago total de cada contribuyente (12).

Entre las rentas cedulares se consideró la predial urbana, la rústica y un gravamen a los terrenos eriazos, calculado sobre el valor de la propiedad. Esta última imposición nunca se ha hecho efectiva. Además, en la ley 7904 se consideró como beneficio gravable con impuesto a las utilidades los resultados de la explotación directa de predios rústicos, la compra-venta habitual de inmuebles y la lotización, urbanización y construcción de casas y edificios.

Posteriormente, mediante la ley 10841 se gravó también las ganancias de capital derivadas de la venta de casas y fincas en forma esporádica. Sin embargo, la ley 15225 varió después este concepto en relación especialmente de las personas juridicas y recientemente la ley 16900 ha derogado el impuesto, creando en su reemplazo un tributo adicional a la alcabala de enajenaciones, con la misma tasa del 6 , pero que obligatoriamente debe pagar el enajenante.

En cuanto a la renta predial, el impuesto original fue modificado en parte por las leyes 13528 y 15270 (Art. $\left.114^{\circ}\right)$, y, últimamente, por la ley 16900 . Esta nueva disposición legal también ha variado el régimen impositivo de los terrenos sin construir.

Con arreglo al régimen vigente, la renta que producen los predios rústicos y urbanos está gravada en diversas formas:

a) Con el impuesto a las utilidades y el predial, si se trata de renta real percibida por inmobiliarias y otra clase de personas colectivas.

b) Con el impuesto predial y el de utilidades, si se trata de predios rústicos explotados por su propietario directamente.

c) Con el impuesto predial, si se trata de renta ficta o presunta, por estar el predio urbano utilizado por el propietario, sea esta persona natural o colectiva.

12 Juan Lino Castillo Estudio crítico del anteproyecto de ley de Impuestos a la Renta del año 1960. Cámara de Comercio, Imprenta Gil, Año 1951, Pág. 1. d) Ccn el impuesto predial, si se trata de renta real percibida por personas naturales.

La renta real es el importe del arrendamiento total del predio duranie un año completo. La renta presunta se determina en caso de ocupación por el propietario y para ello se considera un porcentaje del valor del predio, variable del $3 \%$ al $6 \%$ en fundos rústicos y del $4 \%$ al $8 \%$ en fincas urbanas, según los usos a que está destinada.

La renta gravable con el impuesto predial se determina mediante la deducción de un porcentaje del $10 \%$ para los predios rústicos y del $25 \%$ para los urbanos por conceplo de gastos de conservación, reparaciones, malas deudas, administración y seguro; además, se permite la deducción de determinados arbitrios e intereses hipotecarios.

En el Perú sólo se grava directamente el derecho de propiedad como tal, ya sea a través del impuesto a los terrenos sin construir o mediante la imposición a las tierras eriazas, pero en este último caso sólo en forma nominal, pues jamás se ha puesto en vigencia dicho gravamen. El único intento de hacerlo fue en el año 1949 a través de la Ley 11061, pero tampoco tuvo efectividad.

En síntesis, en el Perú actualmente la propiedad inmobiliaria está afecta directa o indirectamente a los tributos siguientes:

\section{En el caso de transferencia}

Si la disposición de la propiedad es a título oneroso, cualquiera que sea el medio, tipo de operación o contrato (compra-venta, aporte, adjudicación, remate, etc.), está sujeta al pago del $12 \%$ por concepto de doble alcabala (ley 16900). El impuesto se calcula sobre el valor convenido entre las partes, salvo que dicho valor sea inferior en $20 \%$ al valor real, en cuyo caso se aplica sobre este último con un recargo del $100 \%$. Para este efecto el valor real se determina con arreglo al arancel y el reglamento de tasaciones elaborado por el Cuerpo Técnico oficial.

Si la transferencia es por donación o herencia, se aplica la alcabala de sucesiones (ley 2227) y el impuesto a la masa hereditaria (leyes 7873 y 10545) salvo que, en el caso de donación, expresamente se excluya de la colacićn de bienes. Ahora bien, si el contrato de transferencia es utilizado además como comprobante de recepción de pago, entonces, adicionalmente a los tributos referidos tendrá que abonarse el $1 \%$ de timbres fiscales. Sin embargo, en el contrato privado de venta, en cuanto expresa una obligación de pago, no paga timbres ni debe 
inscribirse en el Registro de Ventas, porque la alcabala de enajenaciones que grava dicha operación de transferencia es sustitutoria del impuesto de timbres (ley 15225).

\section{En el caso de garantia}

Si la propiedad es utilizada como garantía hipotecaria, se entiende que la constitución de la misma implica un reconocimiento de deuda, y se grava el contrato con un impuesto de registro con la tarifa del $2 \%$ (Res. del Tribunal Fiscal No 3354 de 8 de marzo de 1968).

\section{El derecho de propiedad}

La propiedad de un terreno urbano sin construir, por el hecho de estar en esa condición, está sujeta al pago del impuesto a los terrenos sin construir. Este tributo deben satisfacerlo tanto los propietarios individuales, como los propietarios de urbanizaciones o lotizaciones, por los lotes que no hubiesen sido aún transferidos. La tarifa varía desde el $0.25 \%$ anual hasta el $3 \%$, según quien sea el contribuyente y la situación del predio. La tarifa del impuesto se aplica sobre el valor inicial de compra y después de un periodo sobre el valor de arancel.

\section{Beneficios derivados de la propiedad}

Al respecto debemos considerar cuatro clases:

4. 1 La renta real que produce el inmueble.

4. 2 La renta que se presume representa la utilización directa por el propietario.

4.3 La renta que se obtiene en la transferencia de inmuebles, cuando ello constituye el giro del contribuyente.

4. 4 Las ganancias de capital reales o presuntas provenientes de la disposición de la propiedad.

\section{A continuación tratamos someramente cada caso:}

\section{1 Renta real de un inmueble}

Esta riqueza está gravada con el impuesto predial en el caso de personas naturales, y además con el impuesto a las utilidades si el contribuyente es una persona colectiva. En el caso de playas de estacionamiento, además del impuesto del 15\% (ley 14947) en favor de las municipalidades, debe pagarse impuesto a las utilidades, quien quiera que sea el contribuyente. La tarifa del impuesto predial es del $7 \%$ que se aplica sobre los arrendamientos. Para establecer la renta líquida gravable hay derecho a deducir, sin comprobación, un $25 \%$ por concepto de supuestos gastos en reparaciones, seguros, etc. Los recibos de arrendamiento pagan impuesto de timbres con la tarifa del 11 por mil.

La renta afecta con el impuesto predial, si es perciblda por una persona colectiva está gravada, además, con el impuesto a las utilidades, cuyas tarifas van desde el $5.5 \%$ al $38.5 \%$, más un $2 \%$ por impuesto pro-desocupados. Además, el contribuyente tiene opción de deducir intereses hipotecarios y gabelas cuando soporta el pago de estos últimos. El impuesto predial en ese caso resulta ser un pago a cuenta del de utilidades.

Por otra parte, la renta de predios neta que queda después de haberse deducido los impuestos referidos, resulta gravada finalmente con el impuesto complementario. Este tributo será de tasa progresiva o fija, según sea el contribuyente persona natural o colectiva.

\section{2 Renta presunta}

Cuando el propietario ocupa el inmueble o tratándose de un predio rústico que lo explota directamente, se presume una renta. Esta presunción equivale a un porcentaje que varía desde el $4 \%$ al $8 \%$ en inmuebles urbanos y que se aplica en atención al valor del predio y el fin de su utilización. En el caso de predios rústicos, el porcentaje oscila entre el $3 \%$ y el $6 \%$. La tarifa del impuesto es del $7 \%$ y recae sobre una renta liquida determinada en la misma forma que si se tratara de una renta real. Tratándose de predios rústicos, independientemente del impuesto predial, debe pagarse también impuesto a las utilidades y pro-desocupados que gravan los beneficios de la explotación, con las tasas ya mencionadas.

Finalmente, esta renta presunta también se considerará, previa deducción de los impuestos cedulares referidos, dentro de los beneficios gravables con el impuesto complementario de tasa progresiva. Este último tributo tiene como tasa de impuesto, porcentajes que van desde el $7 \%$ al $30 \%$, aplicándose esta última escala a toda suma líquida que exceda de los S/. 100,000.00.

\section{3 La renta proveniente del comercio en predios}

Cuando el contribuyente tiene como actividad económica la compra y venta de inmuebles y/o la construcción de fincas para su venta, los beneficios derivados de dicha actividad tienen la condición de renta sujeta al impuesto a las utilidades y pro-desocupados y, además, al impuesto complementario. En el caso de este último se aplicará complementario de tasa progresiva si 
el sujeto pasivo es una persona natural; y, si el contribuyente es una persona colectiva, deberá satisfacerse entonces el complementario de tasa fija, con las tarifas que corresponda según se distribuya, capitalice, o permanezca sin repartir la utilidad liquida obtenida (leyes 15228 y 16900).

\section{4 Ganancias de capitales reales o supuestas}

El Tribunal Fiscal ha establecido jurisprudencia (en nuestro concepto controvertible, pues carece de base legal) en el sentido de que los beneficios derivados de operaciones no habituales de aporte de inmuebles, adjudicación de inmuebles en vía de reducción de capital de una sociedad o, como consecuencia de su disolución y liquidación, o de simple compra-venta, están sujetas al impuesto a las utilidades y al impuesto complementario, como si se tratara de ingresos periódicos que tienen la condición de renta realizada. (Resoluciones del Tribunal Fiscal Nos. 1153 de 24 de marzo de 1965 y 2197 de 4 de noviembre de 1966).

\section{Pago de servicios}

Quien ocupa un predio, sea como propietario o inquilino, debe satisfacer los arbitrios de alumbrado, baja policia, jardines y parques. Estos tributos, cuyas tarifas oscilan en total entre el $6 \%$ y el $10 \%$, se calculan sobre el valor anual de los arrendamientos. Si el predio es habitado o utilizado por el propietario se estima la merced conductiva en un $8 \%$ del valor real de la finca. Dentro de este rubro también podemos considerar los cánones mineros y de petróleo.

En conclusión tenemos, que dada la variedad de tributos existentes y de situaciones sujetas a imposición, no sería recomendable simplemente agregar el Impuesto Territorial, sin antes ordenar y definir orgánicamente todos los hechos imponibles y gravámenes aplicables dentro de un impuesto único a la propiedad. Ello facilitaría el cumplimiento por el contribuyente de sus obligaciones tributarias, aumentaría la recaudación fiscal y evitaria el incidir negativamente sobre el desarrollo de la propiedad en sus múltiples aspectos.

\section{CARACTERES DEL IMPUESTO}

\section{1 Materia gravable}

El objeto primario del tributo en el Impuesto Territorial fue únicamente la propiedad raíz. Ella se equiparó para dichos efectos como "renta de la tierra", en el sentido ricardiano, o sea, como aquella ganancia que representaba su simple posesión o disfrute.

A este tipo de beneficio se ha calificado también como "renta no ganada de carácter permanente", frente al beneficio del cultivo o explotación del predio que se considera como "renta ganada de carácter temporal" (13). Como puede verse, la contribución considera esencialmente que el mero hecho de la titularidad de la tierra, o sea, que ésta sea objeto de un derecho de propiedad, genera un producto económico valorable, pues en la tierra lo que resalta es la propiedad de la misma como facultad de goce (14).

Sin embargo, cabe destacar que desde su inicio, el gravamen fue regulado de tal modo que pudiera ser satisfecha sin menoscabarse el capital que representaba la propiedad del predio afectado. O sea, que el tributo pudiera ser pagado con los resultados económicos que producia o debía producir el inmueble.

Vale decir, que se ha aceptado el principio de que un impuesto sobre el capital debe ser pagado con la renta, aunque sea calculado sobre el capital (15).

El Impuesto Territorial es agrupado técnicamente dentro de los tributos que gravan la propiedad. En tanto que tal, tiene la naturaleza de los llamados "impuestos de producto".

Se entiende por éstos, aquellos que afectan la capacidad de prestación del contribuyente. Grava sus diversas fuentes (en este caso la posesión de tierras y casas) sin tener en cuenta, fundamentalmente, las circunstancias personales del sujeto pasivo de la obligación o contribuyente.

Ello no quiere decir, sin embargo, que la imposición sobre el beneficio o producto que representa la tenencia de la propiedad recaerá sobre un monto bruto estimado. Se considera el derecho a deducir los gastos de producción (gastos de seguro, reparaciones, amortizaciones, etc.) que suscita el ejercicio o conservación del bien.

De ahí que normalmente el objeto del impuesto sea el llamado producto líquido. También recibe el nombre legal de beneficio líquido o utilidad líquida.

13 Jaime García Añoveros Explotación agrícola y contribución territorial. Revista de Derecho Financiero y de Hacienda Pública, Vol. XVII, No 70.

14 Jaime García Añoveros Explotación agricola y contribución territorial. Revista de Derecho Financiero y de Hacienda Pública, Vol. XVII, No 70.

15 Idem. 
Esta condición de impuesto de producto que tenía la contribución territorial rigió hasta mediados del siglo pasado. Desde alli comenzó a modificarse como resultado de la "subjetivización de los conceptos impositivos".

Las nuevas concepciones dieron lugar a reformas tributarias. Los impuestos de producto, o por lo menos la gran mayoria de ellos, pasaron a ser impuestos sobre la renta, o sea, imposiciones en las cuales al calcularse el gravamen se considera no sólo los gastos de producción, sino también deducciones especiales. Estas son las motivadas por las circunstancias personales del contribuyente que disminuyen su capacidad de prestación; por ejemplo: número de hijos, enfermedades, mínimo de existencia, etc.

Esta renovación dio origen a que se produjera una separación clara de los dos hechos económicos que habian pasado a constituir con el transcurso del tiempo la materia gravable con el impuesto territorial: la propiedad predial en si y los beneficios de su explotacićn.

El avance de la economía hizo visible la necesidad de contemplar no sólo las urgencias fiscales inmediatas, sino también de preservar las fuentes productoras de los ingresos fiscales. Ello en armonía con una politica de desarrollo sana y equilibrada.

Nació así el principio vigente de considerar la capacidad tributaria como medida de la imposición. La naturaleza real del Impuesto Territorial fue enervada por consideraciones que habían sido privativas de los impuestos personales.

Por eso, ahora, la doctrina preconiza que se determine el monto afecto al impuesto contemplando la posibilidad de aceptar mayor variedad de deducciones. Se atiende a las circunstancias económicas y legales particulares de cada contribuyente y de cada predio.

Como resultado del avance de la técnica y el sentido de justicia tributaria, ha quedado determinado que la materia gravable con el Impuesto Territorial debe ser el producto líquido. El mismo tratamiento se sigue, aunque éste no sea un rendimiento real sino presunto. De ahi que resulte aconsejable, como hemos señalado, que a través de una ley orgánica se estructure como un todo los diversos tributos que inciden sobre la propiedad.

Estas modificaciones han repercutido indudablemente en el rendimiento fiscal del tributo. Pero, asimismo, ha asegurado su permanencia como impuesto socialmente justo.

Interesa fijar entonces cuál es la base tributaria que permite establecer dicho beneficio líquido imponible.

\section{2 Base tributaria para establecer la materia gravable}

La base tributaria en el impuesto sobre la propiedad es su valor. Ello significa evaluarla.

La función de evaluación supone, como indica Taylor (16), dos momentos: a) incluir la propiedad imponible en las listas o padrones de impuestos; y, b) atribuirles un valor con fines impositivos.

Ninguno de estos momentos es sencillo, como pudiera suponerse. Inscribir o catalogar los predios supone un conocimiento por parte de las autoridades impositivas de que esa propiedad existe. El segundo, o sea la valorización, plantea el problema de cuál es el procedimiento o medida más adecuado.

Ambos factores se complementan y no se puede esperar o ejercitar el impuesto si no se satisfacen los dos en armonia con el sistema integral que se adopte para determinar el monto imponible.

Ahora bien, el sustento de enlace de ambos es el catastro. Este, a su vez, también se confecciona según el objetivo que señale la política común adoptada para tasar el bien: extensión, ubicación, características topográficas, calidad de la tierra, clase de explotación, tipo de cultivos, rendimientos, etc. Además los catastros incluyen para el efecto apreciaciones sobre el valor, producción y beneficios de arrendamiento.

En cuanto al conocimiento oficial de la existencia de la propiedad, la práctica general ha sido la de confiar en el mismo contribuyente para registrar las partidas de propiedad imponible.

Este método hace innecesaria una investigación detallada por parte del que evalúa, pero deja amplias brechas a la evasión fiscal (17). Por eso, se ha complementado con la investigación del propio organismo controlador.

Al respecto, no existe razćn alguna para que el Estado no pueda llevar a cabo este servicio a través de los gobierno locales. Estos podrian ser los encargados de levantar los planos catastrales. Adicionalmente, debe tenerse presente la posibilidad actual de comparar las fotografías aéreas con los mapas catastrales. Resulta así un método útil para controlar la inclusión de las propiedades inmobiliarias en los registros fiscales.

En ese sentido los registros o padrones prediales actuales podrían complementarse mediante una declaración especial que podría exigirse a los propietarios y los

16 Philip E. Taylor, Economía de la Hacienda Pública. 17 Idem. 
planos aerofotográficos que cubren casi todo el territorio nacional.

En relación al valor de las propiedades, en los origenes del impuesto se consideró la extensión de los predios como factor básico determinante de su valor.

Posteriormente se superó esta etapa al hacerse evidente que el área de un inmueble no podría ser el único elemento para dar la medida de su valor.

Las tierras no son todas iguales. Su calidad topográfica, posibilidad de cultivo y otros factores de la naturaleza las hace distintas. Ello originó que la evaluación de los inmuebles se hiciera también considerando los aspectos cualitativos de los predios y los resultados que podrían obtenerse de su explotación normal. Sin embargo, las dificultades no disminuyeron. Era imposible obtener valuaciones justan ante normas tan excesivamente generales que no podían contemplar las particularidades que genera la explotación predial, como por ejemplo: cambio de cultivos por plagas, variación de la demanda, fluctuación de los precios de los productos, acción de la misma naturaleza como desbordes, sequías, etc.

Las dificultades expuestas llevaron finalmente a considerar como método adecuado para fijar la base imponible o valor, el precio de mercado de los inmuebles. Para el efecto se contempló su reajuste dentro de cieria periodicidad o con motivo de la variación de cualquier elemento determinante de su valor.

\section{El Catastro}

Tal como se ha señalado, el catasiro es el instrumento básico para hacer efectivo el impuesto. Contiene la historia legal, económica y física del predio.

El catastro comprende como clases de operaciones: las agronómicas y las planimétricas (18).

Las primeras se refieren a los diferentes cultivos de las tierras. Las segundas tienen por objeto la medición del pais y la representación gráfica de aquellos resuliados en los planos catastrales, con inserción de los predios urbanos y rústicos, éstos últimos bien por parcelas (catastro parcelario) o referidos a unidades de explotación (catastro de explotación).

El sistema llamado de explotación para los predios rústicos ha traído aparejadas dificultades de carácter técnico. Supuso no sólo una individualización de los

18 Gabriel Franco, Principio de Hacienda Pública, Edit. Ciencias Económicas S. R. C., 1957, Pág. 305. predios, sino también su agrupación con relación al centro de la explotación agraria. Esta fue la razón que llevó a los expertos a pronunciarse, casi sin excepciones, en favor del catastro parcelario.

En el catastro parcelario, como indica Gabriel Franco: "la parcela se define como una porción continua de terreno, perfectamente delimitada, perteneciente al mismo propietario y de la misma categoría de cultivo o clase de predio" (19).

La parte planimétrica de este catastro comprende las triangulaciones geodésicas de los tres órdenes y las topográficas de cada demarcación municipal, enlazadas con aquéllas; el levantamiento del plano perimetral de cada término y de los polígonos topográficos; divisiones parcelarias de dichos poligonos y de deslinde de cultivos, dentro de cada parcela (20).

"Las dificultades inherentes a la valorización por separado de cada una de las parcelas obliga a seguir un sistema de promedios. Este sistema consiste en una clasificación de las parcelas tomando como muestra unidades típicas. Primero se ordenan los predios según el cultivo a que se dedican: cereales, huertas, jardineria, viñedos, prados, bosques, etc. Una vez hecha esta clasificacićn se calcula cuál puede ser el rendimiento de una parcela de primera, segunda y tercera calidad, habida cuenta de la manera como se explotan. Los cálculos se hacen con arreglo a los precios corrientes del mercado referidos, según la práctica de los distintos países, al comienzo de los trabajos o bien en la ćpoca en que se verifican las estimaciones." (21)

El catastro comprende también la extensión y situación de las fincas urbanas y el levantamiento de los planos de las manzanas o cuadras de las poblaciones.

Ahora bien, la base de la imposición se extiende a la superíicie edificada y a los terrenos ocupados. Pero el impuesto no se contenta con gravar la superficie, se diferencia con arreglo al número de pisos, al destino de las construcciones, a la importancia de la población y a la situación de las explotaciones y almacenes. De esta suerte, se logra un esquema articulado en clases, muy diferenciado, en el que se aplican cuotas distintas.

"Es inadmisible el sistema que pretende hallar una medida de la base imponible en el número de puertas y

19 Gabriel Franco, Principio de Hacienda Pública, Edit. Ciencias Económicas S. R. C., 1957.

20 Gabriel Franco, Principio de Hacienda Pública, Edit. Ciencias Económicas S. R. C., 1957, Pág. 306.

21 Idem, pág. 305. 
ventanas. Los huecos son un elemento, entre otros muchos, para determinar el valor del edificio y es difícil circunscribir lo que se ha de entender por puertas $y$ ventanas. En Francia, quedó demostrado lo perjudicial que es este sistema para la salud pública, pues forzosamente influye en la forma de edificación." (22)

En el catastro también se consigna el valor locativo o de arrendamiento de las fincas o parcelas y responde a la idea de gravar por separado las utilidades que percibe el propietario, como dueño de las fincas, y las que obtiene el arrendatario o colono.

En diversas legislaciones se conjuga en el catastro el valor de mercado con la estimación del líquido imponible sobre la base del alquiler, acompañada de los procedimientos complementarios a los que ya hemos hecho referencia.

En resumen, para determinar el valor del predio rústico y urbano, según sea el caso, se considera tanto la extensión del inmueble como el producto que le corresponde por unidad de superficie, su valor de mercado y su renta real o presunta. Vale decir, que en el catastro para fijar el valor se parte del supuesto de que el precio de venta de los predios guarda una relacićn constante y necesaria con su rendimiento.

El catastro considerado como una de las realizaciones mós periectas de los impuestos reales cuenta con muchos detractores. Las principales críticas que se le hacen pueden concretarse en los argumentos siguientes:

1. Los catastros adolecen de extraordinaria rigidez. No es posible aplicar un criterio uniforme en la valorización de los predios, debido a los cambios que experimentan los precios en el transcurso de los años invertidos en los trabajos. El valor de los inmuebles cambia debido al progreso de la agricultura, a las variaciones de las técnicas de cultivo, a la apertura de vías de comunicacićn, a la pérdida o conquista de mercados, etc.

2. Las modificaciones del arancel, repercuten en el valor de los productos y ello se traduce a su vez en un aumento del valor del inmueble, cayéndose asi en un círculo vicioso.

3. La imposibilidad de realizar un catastro rápido y completo que se mantenga actualizado.

Los argumentos expuestos podrian llevar a desechar el sistema de catastro como procedimiento para determinar la base imponible de la contribución territorial. Sin embargo, ello no puede hacerse porque hasta ahora

22 Gabriel Franco, Principios de Hacienda Pública, Edit. Ciencias Económicas, 1957. no se ha encontrado ningún sustituto mejor para reemplazarlo.

En diversos países se ha considerado como una solución a los problemas que plantean los aspectos de control, valorización, acotación y recaudación de este tributo sobre la tierra, el ceder esta fuente de recursos en parte a los municipios. Se ha llegado a la conclusión de que los gobiernos locales son los únicos que tendrian la posibilidad de efectuar revisiones periódicas y mantener actualizado el valor de los predios. En dicha forma se resuelven varios problemas fundamentales del impuesto sobre la tierra.

Hay propiedades inmobiliarias que ofrecen dificultades prácticas desde el punto de vista de su acotación. Las minas o tierras que contienen minerales $u$ otros recursos agotables y los bosques o tierras utilizadas para la producción de maderas no pueden ser gravadas lo mismo que los fundos o predios urbanos.

Las tierras que contienen recursos minerales, si se les grava anualmente sobre una base impositiva que represente su valor real presente, puede fomentar una rápida y ruinosa utilización de esos recursos.

"Por otra parte, la imposición de los terrenos forestales, como señala Franco, presenta problemas parecidos. El uso económico de los recursos forestales exige que los árboles se corten únicamente a la edad más adecuada para la producción de madera. Y la política de conservación exige que los árboles cortados se remplacen por nuevos árboles en período de crecimiento. La aplicación del impuesto sobre la propiedad a las tierras forestales valoraría anualmente esas tierras a unos precios que incluyera el valor presente de los árboles plantados en ella. El largo período para que los árboles alcancen un tamaño que les permita ser económicamente utilizables, llevaria consigo el pago de una sucesión de impuestos anuales antes que se obtuviese beneficio alguno a la venta del producto. Resulta claro que esto equivale a dar una prima a la corta temprana, y desalienta la plantación de árboles para remplazar a los cortados".

Las dificultades entonces no radican tanto en el impuesto, sino en el conflicto práctico entre la política fiscal y la politica de conservación. Al respecto es indudable que una política físcal adecuada puede eliminar el problema de la necesidad de talar por razones fiscales $y$, al mismo tiempo, contemplar una legislación apropiada que combine impuestos anuales bajos sobre tal propiedad con impuestos especiales sobre la producción cuando el producto se lleve al mercado. 
En cuanto a las dificultades que presenta la confección rápida del catastro, conforme hemos señalado, puede superarse en breve término sobre la base de los trabajos existentes, los padrones prediales, las declaraciones que pudiera exigirse a los contribuyentes y los mapas de fotografías aéreas. A través de dichos elementos ya no se puede pretextar una imposibilidad o demora que lo haga inoperante ni de costos ingentes. Quedan asi salvadas objeciones importantes que se hacian a la posibilidad de contar rápidamente con un catastro eficiente.

En relación con la fotografía aérea, concretamente, algunos especialistas en esta materia estiman que los resultados obtenidos mediante ella superan los conseguidos por los procedimientos tradicionales. "Los datos obtenidos mediante la fotografía aérea no deben tenerse como de inferior condición técnica a los obtenidos por los topógrafos, ya que en éstos caben errores y discrepancias que escapan a toda inspección, en tanto que el automatismo de la fotografía aleja todo temor. Por esto, puede afirmarse que todas las características catastrales son mejoradas por el procedimiento fotográfico." "En lo que se refiere a las geométricas es indudable la apreciación de conjunto que hace la fotografia al mismo tiempo que parcela, y el registro de circunstancias no tomadas en cuenta por la brújula, pero que encierran posibilidades de ubicación insospechadas, convirtiendo la placa fotográfica en registro automático de todo el contenido visible en la zona que se utiliza" (23).

\section{3 Determinación del Impuesto}

Fijada la base imponible o valor del predio a través del catastro, viene el proceso de determinación de la materia gravable sobre la cual recaerá el tributo. Esto conlleva la deducción de ciertas partidas cuando sólo se pretende gravar el producto líquido. Al respecto, algunos países contemplan principalmente la deducción de gastos capitalizables o inversiones, mejoras y todos aquellos egresos $\mathrm{y} / \mathrm{o}$ inversiones que contribuyan a la conservación de la propiedad.

En cuanto al monto del Impuesto Territorial, se obtiene a través de dos sistemas tradicionales aplicables al producto gravable: el de cupo y el de cuota.

Por el primero y una vez en posesión de los datos estadísticos proporcionados por el catastro en relación a

23 Gabriel Franco, Principios de Hacienda Pública, Edit. Ciencias Económicas S. R. L., 1957, Pág. 308. la totalidad de la riqueza imponible, se distribuye la suma total de impuesto entre todas las reparticiones politicas, comenzando por las de mayor categoria, las cuales a su vez proceden a repartir las partes pertinentes entre las de jerarquía inferior inmediata, las cuales efectúan el mismo proceso hasta llegar a las entidades politicas locales de categoría inferior, último órgano en estas operaciones, quienes distribuyen la suma asignada a las mismas entre los contribuyentes de la demarcación.

En el sistema de cuota, por el contrario, se fija el tanto por ciento con el cual debe tributar cada unidad de la materia imponible.

Ahora bien, como advierte el profesor italiano Flora, los dos sistemas llevan a los mismos resultados, si los datos concernientes a la riqueza inmobiliaria son exactos. Los paises con un catastro anticuado y que acusa grandes diferencias en las estimaciones suelen acudir al sistema de cupo.

Los paises donde se utiliza ef régimen de cuota, aplican en su mayor parte una tarifa proporcional pero con tendencia a que sea diferencial.

\section{JUSTIFICACION DEL IMPUESTO}

La creación del Impuesto Territorial está justificada principalmente por razones juridicas, económicas, fiscales y sociales.

\section{Fundamentos legales}

Conforme a las nuevas orientaciones del Derecho Tributario, todo hecho económico que implique un movimiento o tenencia de riqueza, al ser indicativo de capacidad tributaria, debe estar gravado con impuestos. La capacidad tributaria resulta ser asi la causa jurídica del impuesto. Interesa establecer entonces si sería válido legalmente considerar la simple propiedad o tenencia de la tierra como un hecho imponible dentro de un sistema impositivo.

Los hechos imponibles o presupuestos de hecho que contemplan los sistemas impositivos -como señala Jarach (24) - obedecen a un criterio, no son producto de antojos. "Ellos no nacen según el capricho de legisladores provistos de fantasias".

Según Sainz de Bujanda, en el estado moderno el poder de imperio ha dejado de ser una fuerza o poder de hecho, para convertirse en un poder jurídico dentro del cauce constitucional (25). Vale decir, que el Estado

24 Dino Jarach, El hecho imponible, Pág. 71 y ss.

25 Fernándo Saiz de Bujanda, Estructura Jurídica del Sistema Tributario. 
utilizando simplemente su poder de imperio no podria exigir tributos sobre la base de cualquier presupuesto de hecho, pues tropezaría con el marco de sus propios fines.

Como apunta López Varela (26), "uno de los motivos fundamentales que ha conducido a la organización del Estado, y por lo tanto al establecimiento de recursos para sostenerlo, ha sido precisamente, el de asegurar la protección de los derechos civiles de los ciudadanos. No se concibe al propio Estado vulnerando sus mismos "fines", con el propósito de levantar impuestos que sólo son medios con relación a aquéllos.

Ahora bien, la doctrina considera tres grandes categorias para establecer los presupuestos de hecho:

a) Recibir un servicio individualizado del Fisco (tasas);

b) Los que han sido beneficiados particularmente con un gasto o ventaja (contribuciones especiales); y

c) Los que poseen la capacidad de pagar o capacidad contributiva. Existe una capacidad contributiva individual y una de la nación en su conjunto.

Berliri (27) ha reducido a impuestos y tasas los tipos de tributos de estas tres categorías, por considerar que aún subsistiendo la segunda categoria como justificativa de imposición, las contribuciones especiales no se diferencian de los impuestos.

Tenemos entonces que desde el punto de vista juridico se comprueba que todos los presupuestos de hecho de los impuestos tienen "naturaleza económica" en la forma de una situación o de un movimiento de riqueza. La propiedad es un presupuesto de hecho de naturaleza económica. Dicho derecho o hecho económico-jurídico o presupuesto de hecho, interesa en cuanto es revelador de una capacidad contributiva.

La capacidad contributiva o tributaria ha sido definida en diversas formas. "Potencialidad de contribuir a las necesidades públicas que el legislador atribuye al sujeto pasivo" (28). "Capacidad de prestación económica, ésto es: se debe abonar el impuesto en relación con la riqueza poseída, capital o renta".

Los aspectos señalados nos llevan a establecer el porqué la capacidad tributaria puede ser o es la causa jurídica del impuesto. Como dice Jarach, si buscamos la causa en el sentido común y no técnico-jurídico, pode-

26 Manuel L. López Varela, Principios Jurídicos de los Impuestos, Pág. 27.

27 Antonio Berliri, Principios de Derecho Tributario, Pág. 318.

28 Dino Jarach, El hecho imponible, Pág. 73. mos remontarnos de causa en causa, hasta llegar a la causa primera de todas: se paga el impuesto porque la ley manda, porque el Estado tiene el poder de imperio y porque tiene necesidad de procurarse los medios pecuniarios para satisfacer sus finalidades. Evidentemente, tomando el camino de los "porqués", el campo del Derecho Tributario resulta chico y hay que entrar en el constitucional y hasta en el Derecho en general, para llegar hasta la meta jurídica y razones de la existencia del Estado, de su poder y de sus necesidades.

De ahí que la causa técnico-jurídica del impuesto no puede ser buscada sino en la causa próxima. En la causa que es inmanente en el mismo hecho jurídico de la relación tributaria y explica su naturaleza y sus características. Esta causa del tributo resulta ser entonces "la circunstancia o el criterio que la ley asume como razón necesaria o suficiente para justificar que de verificarse un determinado presupuesto de hecho, derive la obligación tributaria" (29) y, ¿Cuál es esta circunstancia o criterio que la ley considera razón básica?.

Los tratadistas y todas las constituciones modernas, casi sin excepción, señalan como tal la capacidad contributiva (30). Por ello se afirma que la causa jurídica de los impuestos es la capacidad tributaria que es un principio fundamental (31).

Esclarecido que la capacidad contributiva es la razón determinante o criterio suficiente para que pueda establecerse o exigirse un impuesto, interesa precisar si el derecho de propiedad con todos sus atributos, uso y disfrute de un bien, es económicamente una riqueza que revela dicha capacidad. Indudablemente que sí.

Históricamente la primera expresión de la capacidad contributiva fue incluso la extensión de los predios. La propiedad como tal representa un valor económico. Es un bien que significa y puede generar riqueza. El ser propietario conlleva la condición de ser capaz tributariamente. De tener capacidad tributaria. Aun cuando la situación económica general del contribuyente pudiera en determinado caso ser deficitaria, no hay duda que la misma en la parte que estuviere siendo representada por propiedades, estaría mejorada o capacitada positivamente en el patrimonio. Pero únicamente, por supuesto, hasta lo que pudieran significar dichos bienes en el estado económico total.

29 Dino Jarach, El hecho imponible, Pág. 82.

30 Roberto Tamayo, El Contribuyente, Pag. 61, Edit. Perrot.

31 Roberto Tamayo El Contribuyente, pág. 63, Edit. Perrot. 
La propiedad es un derecho de naturaleza económica que es considerado en casi todas las legislaciones como un presupuesto de hecho, al cual la ley vincula el nacimiento de la obligación tributaria. Ello es así porque la propiedad genera una capacidad tributaria que debe ser considerada como presupuesto de hecho gravable.

Los conceptos expuestos nos llevan al último problema: ¿Es la propiedad un hecho imponible o presupuesto de hecho aceptable por la Constitución?. La respuesta es afirmativa. Asi se señala expresamente en nuestra Carta Fundamental. El artículo $31^{\circ}$ dice: "La propiedad, cualquiera que sea el propietario, está regida exclusivamente por las leyes de la República y se haya sometida a las contribuciones, gravámenes y limitaciones que ellas establezcan." En el numeral $34^{\circ}$ se señala: "La propiedad debe usarse en armonía con el interés social. La ley fijará los límites y modalidades del derecho de propiedad".

Luego, en el aspecto estrictamente juridico hay fundamentos legales suficientes que justifican que se grave la propiedad con un impuesto territorial, rústico y urbano.

\section{Razones Económicas}

En el campo económico, los fundamentos para la creación del Impuesto Territorial, son igualmente claros.

La magnitud del valor de la propiedad territorial en el país es un hecho económico que constituye razón plena para gravarla, en cuanto es un elemento revelador de una riqueza que no está afecta en todos sus aspectos imponibles. Si bien ello puede justificar el tributo por una parte, también lleva a la necesidad de hacerlo en forma orgánica para no gravar en forma desarticulada dichos aspectos y crear efectos negativos que lleven a una paralización de su desarrollo. En cuanto al valor de la propiedad en el Perú, según los estudios realizados por la Organización de Estados Americanos y el Banco Interamericano de Desarrollo en el Programa Conjunto de Tributación para una reforma impositiva, se obtuvieron los siguientes resultados:

\section{Lima y alrededores:}

En dicho trabajo se tomó como base el plano confeccionado en mayo de 1963 por la Oficina Nacional de Planeamiento y Urbanismo y se consideró únicamente las áreas calificadas como urbanas ocupadas, urbanas en proceso y disponibles para uso urbano. El trabajo abarcó exclusivamente los Distritos de Barranco, Bella- vista, Breña, Callao, Chorrillos, Lima, Lince, La Victoria, La Punta, La Molina, Miraflores, Magdalena del Mar, Pueblo Libre, Puente Piedra, Rímac, Surco, San Miguel, Surquillo, San Isidro, Santa Rosa, San Martín de Porres, Villa Maria del Triunfo, Ate y Comas. En este trabajo no se consideraron las zonas urbanas del resto del país.

Los resultados en soles oro, fueron:

a) Area urbana: $S / .24,279^{\prime} 400,000.00$

Se estableció restando de cada Distrito las calificadas como urbanas en proceso disponible para uso urbano, semirrústicas, eriazas bajas, agricolas, eriazas irrigables, playas, cerros y otros usos (parques, plazas, paseos y edificios públicos). Igualmente se consideró las superficies asignables a calles.

b) Superficie edificada: entre $S / .32,460 ' 000.000 .00$ y 81,150 '000.000.00

Se estimó considerando las áreas ocupadas con construcciones y como valor de éstas, un precio por metro cuadrado que va desde los $\mathrm{S} / .500 .00$ hasta los $\mathrm{S} / .2,000.00$, según los diversos tipos de construcción y su antigüedad.

c) Area urbana en proceso de urbanización: S/. 3,407'700,000.00

Se consideró un área disminuida en un $40 \%$ (parques y superficies libres), y a un precio promedio de $\mathrm{S} / .300 .00$ por $\mathrm{m} 2$.

d) Superficie edificada en proceso de urbanización: $\mathrm{S} / .6,816^{\prime} 000.000 .00$

Se consideró un porcentaje de un $50 \%$ y a un precio promedio de S/. 1,200.00 por m2.

e) Area disponible para urbanización: S/. 5,186’000.000.00 Se depuró de la superficie la que pudiera utilizarse en calles y áreas libres y se evaluó la restante a un promedio de S/. 200 por $\mathrm{m} 2$.

\section{Predios rústicos}

El trabajo de estimación se limitó a las superficies agropecuarias según el Primer Censo Nacional y datos de la Dirección Nacional de Estadística y Censos. Al respecto, sólo se consideraron las explotaciones de 50 - más hectáreas en Lima, Callao, Arequipa, Ica, La Libertad y Lambayeque y de 100 o más hectáreas en el resto del país. Se agruparon los predios según sus características y teniendo en cuenta las posibles extensiones.

Los valores de las tierras fueron tomados del Arancel del Cuerpo Técnico de Tasaciones o de operaciones es- 
peciales de éstos para los casos de tierras cultivables no trabajadas y bosques.

Se consideró sólo un total de 29,624 predios con un área gravable de 14'913,708 sobre un total de 128'521,560, lo que representa un porcentaje del $11.60 \%$. Además, no se incluyeron los predios rústicos no agropecuarios.

Los resultados en soles oro, fueron:
a) Cultivables:
b) Cultivables no trabajadas:
c) Pastos naturales:
d) Bosques o montes:
e) Improductivas:

$$
\begin{array}{r}
10 ' 597,248.400 \\
523,399,900 \\
3^{\prime} 638,069.600 \\
550,460.200 \\
200,053.000
\end{array}
$$

De los datos expuestos tenemos que el valor total resulta ser, para la propiedad urbana y rústica en el Perú, en forma estimada, la cantidad de S/. 110,698'331,100. Este monto es conservador, según ha podido apreciarse de los elementos, factores, inhibiciones y demás circunstancias que se han tenido en consideración para llegar a calcularlos. Ahora bien, es indudable que una riqueza de esa magnitud, por la capacidad contributiva que revela, se justifica en lo económico que esté gravada.

Indudablemente que frente a la consideración económica señalada puede argumentarse en contra: la existencia de otros tributos que gravan diversos aspectos derivados de la propiedad, y que, conforme hemos señalado, ellos serian principalmente, el impuesto a las utilidades, el impuesto predial, el impuesto a los terrenos sin construir que afecta los predios urbanos improductivos, los arbitrios de alumbrado y baja policía que representan el pago de servicios municipales, etc. Ello, sin embargo, no es un factor suficiente como para llegar a la conclusión de que no pueda establecerse la contribución territorial. Dicha argumentación por el contrario debe llevar, tal como se ha señalado con anterioridad en este trabajo, a la reagrupación de los impuestos dentro de normas que contengan debidamente estructurados los principios fundamentales en que ha de inspirarse el reparto de la carga tributaria sobre la propiedad en sus diversos aspectos, pero contemplando como uno de ellos, lo que implica dicho derecho en sí. Es decir, que todos ellos deben convertirse en un impuesto único que abarque diversos hechos imponibles, con tasas diferenciadas, según la naturaleza de cada uno $y$ el fin extrafiscal que se persiga.

En consecuencia, lo que se propone es un Impuesto Territorial que gravando la propiedad con una tasa ade- cuada, no desaliente la explotación productiva rústica y urbana y resulte en cambio onerosa para las propiedades improductivas, motivando así la desconcentración rústica y la redistribución de la tierra según esquemas de tenencia más productivas, además de la redistribución del ingreso que ello implique. Se obedecería asi a uno de los postulados de la Carta de Punta del Este que el Perú ha suscrito.

\section{Razones Fiscales}

Dentro de la urgencia de nuevos recursos públicos para equilibrar el presupuesto nacional y la necesidad de eliminar el déficit fiscal como uno de los factores que atentan contra la estabilidad monetaria, se presenta el Impuesto Territorial como una fuente importante de ingresos.

El Perú es uno de los pocos países en el mundo donde todavía no existe el Impuesto Territorial. Ello no puede justificarse cuando hay una crisis fiscal y existe una riqueza que dado su valor y rendimiento puede gravarse con menor incidencia que otros tributos en el proceso inflacionario. El Impuesto Territorial es probablemente uno de los pocos gravámenes, cuya traslación todavia controvertida, no puede argumentarse como una razón definitiva en su contra.

Ahora bien, considerando que este tributo persigue como finalidad fiscal inmediata el incremento recaudatorio, conviene referirse a si ello podría conseguirse o no.

Al respecto, es indudable que ello se podría conseguir en gran proporción. Primero, porque existen elementos de información económica que acreditan la existencia de una riqueza que está en condiciones de rendir la tributación pensada. En segundo término, porque también hay elementos de control que permiten hacer viable la posibilidad de acotación, control y recaudación del impuesto.

En cuanto al rendimiento cuantitativo del impuesto el monto inicial debe superar los 500 millones de soles. En efecto, aplicando la tarifa proporcional de $1 / 2 \%$ que se ha propuesto sobre el valor mínimo de la propiedad urbana y rústica, estimado en 110,698'331,100.00 al año 1963 , puede estimarse el rendimiento inicial de este tributo en alrededor de 500 millones de soles. Es decir, en algo menos del $1 / 2 \%$ determinado sobre la cifra señalada, pues creemos que las deducciones que deben contemplarse (intereses hipotecarios, seguros, bajos rendimientos por causas naturales, o de mercado, etc.) no quedarán contrabalanceados de inmediato por la in- 
corporación de otras propiedades y el mayor valor real de éstas, hasta que no esté debidamente confeccionado el catastro nacional.

Sin embargo, dicho rendimiento casi seguro puede considerarse suficiente para su implantación en la actual coyuntura económica, teniendo además en cuenta la imposibilidad de acudir a otros impuestos, por el incremento que ellos podrian representar en la presión tributaria y sus efectos nocivos en el desarrollo de la economía nacional.

Finalmente, este tributo resulta también fiscalmente justificado, no sólo por su seguro rendimiento, sino porque también no se contradice con los fines político-sociales que se puedan obtener a través del mismo.

\section{Razones sociales}

El Impuesto Territorial tiene razones sociales-tributarias que lo justifican plenamente.

Este tributo constituye, según los tratadistas, un instrumento importante para promover la reforma agraria, a través de tasas progresivas que graven la propiedad cuando sea improductiva o cuando sus rendimientos sean insuficientes por circunstancias imputables a sus propietarios, obligando asi a éstos a una parcelación o transferencia de las tierras.

Igualmente, resulta plausible la creación del Impuesto Territorial por cuanto a través de él se persigue en cierta forma cumplir en algo el concepto de justicia tributaria, al tratar de gravar la propiedad predial cuya determinación cuantitativa resulta casi imposible de establecer debidamente. Nos referimos a los casos de arrendamientos de favor o simulados. También a aquellos resultados de explotaciones agrícolas que resultan igualmente difíciles de controlar en la práctica, por el costo que demandaría establecer la realidad de los productos obtenidos y su valor por cada parcela o predio rústico.

Es conocido que en la administración tributaria no existen elementos suficientes, ni técnicos, para determinar en cada distrito del país, región, valle y predio, cuáles son exactamente los resultados de las diversas cosechas cuya negociación normalmente se realiza mediante medios, personas y circunstancias que en la mayoría de los casos resultan fuera de la esfera de acción fiscal inmediata.

Por otra parte el Impuesto Territorial resulta ser un instrumento muy útil en los paises latifundistas, cuando utilizando tarifas progresivas se incentiva la parcelación de la propiedad improductiva.
Finalmente, este tributo también se justifica como medio de redistribución del ingreso, dentro del objetivo social de obtener un reparto más justo de la presión fiscal que permita a su vez satisfacer al Estado las necesidades vitales de los individuos que lo componen.

\section{DISTINCION CON EL IMPUESTO PATRIMONIAL $Y$ EL IMPUESTO AL CAPITAL}

El Impuesto Territorial en su condición de patriarca de los tributos ha sido a veces confundido o integrado bajo la concepción de un Impuesto al Patrimonio o incluso de un Impuesto al Capital.

Las semejanzas del Impuesto Territorial con las otras dos imposiciones reside en que los tres gravan el capital, aunque en distinta esfera de magnitud, pero aparentemente bajo el mismo concepto de propiedad o tenencia de riqueza. Es decir, que no inciden directamente sobre el capital como fuente susceptible de producir renta. Sin embargo, en ellos la tarifa del impuesto es regulada bajo el principio general de que su monto debe quedar dentro de cierto límite, para que pueda ser pagado con la renta efectiva o presunta que el bien o bienes produzcan al contribuyente.

A pesar de estas caracteristicas comunes podría señalarse que los tres tributos mencionados, o sea el patrimonial, el territorial y al capital, son diferenciados claramente en doctrina y en la mayoria de las legislaciones.

Por Impuesto Patrimonial se entiende aquel que considera como riqueza gravable la diferencia positiva que resulte después de deducirle a la totalidad de bienes que una persona posee, tanto el pasivo como el valor de ciertos bienes de uso estrictamente personal o doméstico (32).

El Impuesto Patrimonial comprende asi prácticamente todo el activo del contribuyente, o sea, tanto los bienes inmuebles como los muebles. Ello constituye una de las principales diferencias con el Impuesto Territorial. Este último tributo grava sólo la propiedad de los inmuebles, y dentro de éstos únicamente los predios rústicos y urbanos. El campo de acción del Patrimonial es pues más amplio que el Territorial, pues afecta toda clase de bienes. Además, el Impuesto Territorial afecta el capital en cuanto está identificado con la propiedad de los predios, y en cambio el Impuesto Patrimonial termina afectando en realidad únicamente el capital neto del contribuyente.

32 Manuel Matus, Hacienda Pública, Editorial Universitaria, Chile, Pag. 97. 
En relación con el Impuesto al Capital, éste se caracteriza generalmente por gravar dos hechos económicos distintos. El primero, la propiedad de toda clase de bienes muebles y dentro de éstos principalmente los valores bursátiles; y, el segundo, las ganancias de capital, o sea aquellas utilidades resultantes de la venta de inversiones.

Existe otra diferencia importante entre el Impuesto Territorial y los otros dos tributos: El Patrimonial y el Impuesto al Capital. El Impuesto Territorial grava directamente la propiedad en si de los bienes, e indirectamente el incremento de su valor, al fijarse la imposición de acuerdo con su valorización. En cambio, tanto el Impuesto al Patrimonio como el Impuesto al Capital, consideran como beneficio gravable los incrementos de valor, más que la tenencia en si de los bienes. Ello da lugar a una diferente mecánica en la imposición. Normalmente tanto el Impuesto Patrimonial como el Impuesto al Capital, no se fijan por períodos de un año sino por términos mayores, más o menos regulares (33).

Las diferencias anotadas son las que han dado lugar a que en casi todos los países se distinga en sus sistemas impositivos precisamente en diferentes tributos, tanto la afectación al patrimonio y/o al capital mobiliario del Impuesto Territorial.

\section{PROYECTOS PERUANOS DE IMPUESTO TERRI- TORIAL}

En agosto de 1963 el Poder Ejecutivo remitió el primer proyecto de Impuesto Territorial. Presentaba como caracteristicas las siguientes:

a) Se trataba de un impuesto anual sobre los terrenos rústicos y urbanos y sobre las construcciones. Se aplicaba independientemente de los impuestos a los predios rústicos y urbanos y a los terrenos sin construir vigentes en esa época.

b) Los propietarios eran gravados con tasas diferenciales según la zona del pais donde estuviesen ubicados los inmuebles. La zona de la Selva se consideraba exceptuada del impuesto. La zona de la Sierra tenía tasas inferiores en $50 \%$ a las de la Costa.

c) La tasa se calculaba por metro cuadrado y variaba según la ubicación del predio, su cercania a centros poblados, la importancia de las ciudades y la naturaleza de los cultivos.

33 Mario Fasiani, Principios de Ciencia de la Hacienda, Edit. Aguilar, Pág. 364. d) No se contemplaba la situación personal del obligado al pago, ni los resultados de la explotación del predio y los casos de calamidades, pérdidas y otros que pudieran afectar el bien y la capacidad contributiva del sujeto pasivo.

Este proyecto no prosperó por los grandes vacíos y defectos de su articulado. Los opositores a su dación demostraron que la aplicación de las tasas propuestas resultaban confiscatorias en el caso de los predios rústicos (34).

En julio de 1964 se dio a publicidad un nuevo proyecto de Impuesto Territorial. El articulado propuesto variaba del anterior en cuanto al monto de la tasa y la materia gravable.

Como tasa se contempló un porcentaje variable del cinco for mil hasta alcanzar el $2.5 \%$ anual tratándose de sociedades anónimas, en que los predios rústicos o urbanos estuvieran arrendados a accionistas o a parientes con más de $20 \%$ de participación del capital de éste.

La materia gravable se determinaba en el nuevo proyecto no en razón de la extensión sino del valor del predio. Ello representó un avance importante.

La Sociedad Nacional de Industrias (35) hizo ver los diferentes perjuicios económicos que resultaban de la aplicación del proyecto propuesto por el Gobierno, así como otros aspectos negativos. Los principales podían resumirse en:

a) La creación de un impuesto sobre la propiedad exigible independientemente de los que ya la gravaban.

b) Su incidencia en la economía de las empresas industriales al gravar la propiedad inmobiliaria en general.

c) La falta de justificación para gravar con una tarifa mayor a las sociedades anónimas, sin contemplar que es la forma natural de organización jurídica de las empresas industriales.

d) Su incidencia en el ánimo de los inversionistas en casas-habitación, contribuyendo a aumentar la crisis de vivienda.

e) El no haberse contemplado la posibilidad de deducir intereses hipotecarios, como egreso que disminuye la capacidad contributiva y el no haberse tenido presente la realidad del rendimiento del predio.

34 Principalmente comunicados de la Sociedad Nacional Agraria, la Asociación de Cámaras de Comercio del Perú y la Cámara de Comercio, La Prensa, Agosto de 1963.

35 Oficio 106 de 15.7.64 de la Soc. Nac. Industrias, publicado en "La Crónica" el 7 de agosto de 1964. 
La fuerte crítica que se hizo a este proyecto impidió nuevamente que prosperara la implantación del Impuesto Territorial.

Luego en el año 1966, la Organización de Estados Americanos y el Banco Interamericano de Desarrollo, dentro del Programa Conjunto de Tributación elaborado con el gobierno peruano, presentaron un nuevo Proyecto de Impuesto Territorial.

Las normas contempladas contenian básicamente los mismos principios, aunque estaban más cuidadosamente elaboradas. Como novedad importante se establecía que el impuesto se regularía de acuerdo con el valor de mercado del predio. Este monto a su vez se fijaría a través de la valuación oficial.

Además, se ampliaron las exenciones, dentro de éstas se consideró los predios rústicos con valor inferior a $\mathrm{S} / \mathrm{150,000.00}$ y urbanos de menos de S/. 100,000.00. Así como también se estableció la exoneración de diversos predios según la persona y los fines a que estuvieran dedicados.

Entre las más importantes exenciones de esta clase debe mencionarse los predios de las comunidades indigenas, de asociaciones sin fines de lucro o utilizadas para impartir enseñanza gratuita o de propiedad de cultos religiosos oficialmente reconocidos. Pero, se suprimió en cambio la exoneración contemplada en proyectos anteriores en favor de los inmuebles adquiridos a través de las mutuales o entidades estatales o del sub-sector público independiente.

Sobre la base del proyecto preparado por la OEA-BID, la Comisión Revisora de la Legislación Tributaria presentó un nuevo trabajo a mediados del año 1967.

Este estudio denominado "Anteproyecto de Ley de Tributación directa sobre los ingresos y la tenencia de patrimonios", está dividido en tres libros titulados Impuestos sobre la Renta, Impuesto Territorial e Impuesto Sustitutivo del Gravamen de Sucesiones.

El Libro II se refiere al Impuesto Territorial. Contiene 26 artículos divididos en IX Títulos. El Título Primero se refiere al objeto del impuesto y los sujetos vinculados con la obligación tributaria. Al respecto, señala que se trata de un impuesto anual sobre el valor de los predios rústicos y urbanos que se exigirían independientemente del impuesto a la renta predial, de los terrenos sin construir y demás tributos vigentes. El valor del predio sobre el que se aplicaría el impuesto se determinaría mediante valuación oficial.

Para los efectos de la imposición se considera predios, tanto a los terrenos como a las construcciones o instalaciones fijas y permanentes.
Se entiende por construcciones a las edificaciones 0 fábricas en general; $y$, por instalaciones las adheridas físicamente al suelo, tales como canales, pozos, estanques, molinos, etc. No se consideran las plantaciones ni sus frutos, las maquinarias e instalaciones y edificaciones necesarias para la utilización de la maquinaria, siempre que, separados de ésta, aquellas pierdan su valor o resulten inutilizables.

Están obligados al pago los propietarios o los poseedores, cuando no se pueda determinar el dueño.

El Título II trata de las exenciones. Como principales se establece:

a) El predio rústico con valuación oficial inferior a S/. 200,000.00 trabajado por el propietario y que sea propiedad única.

b) El predio urbano de valor oficial inferior a $S / .100,000$.que sea propiedad única y se utilice como casa-habitación.

c) Los edificios del gobierno o dedicados al servicio público (hospitales, cuarteles de bomberos, etc.)

d) Los predios de sindicatos.

e) Los predios dedicados a instrucción universitaria o enseñanza gratuita.

f) Las iglesias y conventos.

En el Título III se contempla la creación del Padrón Predial. Dicho Registro contendrá los datos referentes a la ubicación, naturaleza, composición, uso y renta del predio, tipo y antigüedad de las construcciones e instalaciones y las generales del contribuyente. Para la vigencia reactualizada del Padrón se establece la obligación de declaraciones periódicas y eventuales.

El Título IV trata principalmente acerca de la materia imponible. En su determinación se admite la deducción de los gravámenes hipotecarios, pero no de los intereses.

Como tasa del impuesto se contempla un porcentaje del ocho por mil anual que en determinados casos, según el uso como vivienda y el valor no superior a S/. 500,000.00, puede rebajarse al cuatro por mil.

En relación con el rendimiento del Impuesto Territorial se señala que los gobiernos locales tendrán una participación y contribuirán a su control. La Superintendencia Nacional de Contribuciones será la entidad encargada de la aplicación, administración y fiscalización del impuesto y se crea el Servicio de Catastro Nacional y el Consejo de Tasaciones. Además se prevé que inicialmente el valor de los bienes será fijado por los contribuyentes con cargo a su fiscalización posterior. 
En coordinación con el Impuesto Territorial, en el proyecto de Impuestos a la Renta se contempla la imposición a los beneficios derivados de la explotación del predio o los que puedan obtenerse en las operaciones de venta, ya se trate de ganancias de capital o de utilidades que tengan la condición de renta.

Como puede apreciarse los proyectos referidos adolecen de omisiones o tienen características tales que los hacen poco aparentes dentro de un planteamiento de reforma tributaria integral para obtener un sistema impositivo justo.

En los últimos dias se ha hablado de un nuevo proyecto de Impuesto Territorial (36).

Por las síntesis de las disposiciones que se han dado a conocer parece ser que está estructurado básicamente sobre el anteproyecto que preparó la Comisićn Revisora de la Legislación Tributaria.

Según las informaciones obtenidas, la única variación estaría en la tasa del impuesto que habría sido reducida y uniformada en el cinco por mil del valor de los predios.

Las críticas al proyecto han versado principalmente acerca de las exenciones contempladas. En ese sentido se ha sostenido que el valor de S/.100,000.00 para los inmuebles urbanos resulta hoy diminuto. Asimismo, se alega que no puede gravarse en la misma forma a predios que constituyen la única fuente de renta de personas que no están en condiciones de trabajar (ancianas, viudas, etc), frente a contribuyentes con recursos económicos importantes que puedan incluso poseer varios predios.

En definitiva, pueden sintetizarse los vacios y aspectos negativos en los siguientes puntos:

a) La creación de un gravamen adicional a la propiedad, no deducible para fijar la renta gravable del contribuyente y que es independiente de los tributos existentes, aumentando así la confusión y la presión fiscal sobre los predios al margen de la capacidad contributiva real.

b) Que no se tenga presente la situación personal del contribuyente. Ya sea en cuanto al monto de su renta 0 a las necesidades particulares por razón de familia numerosa, trabajo, etc.

c) Que no todas las exenciones planteadas son justas, ni responden a fines extrafiscales suficientes para justificarlos.

Podemos, concluir, por tanto, que los proyectos propuestos presentan objeciones técnicas, que los hacen

36 Diario La Crónica, Edición de 23 de mayo de 1968. poco aptos para mejorar nuestro sistema tributario desde el punto de vista estructural. Ellos reflejan la carencia de una política fiscal coherente. En ellos sólo aparece el interés de buscar rendimientos inmediatos al margen de sus consecuencias económicas futuras.

\section{CONCLUSIONES.}

Del estudio realizado del impuesto Territorial y los proyectos existentes, llegamos a las conclusiones siguientes:

1. Que debe hacerse una reforma tributaria. Como parte integrante de ella debe contemplarse la restructuración de los diversos impuestos que gravan la propiedad predial e involucrarse como uno de ellos el Impuesto Territorial. Es decir, que no debe crearse dicho tributo en forma independiente y adicional a los existentes, aumentando el desorden de nuestra legislación impositiva.

2. La restructuración de dichos tributos debe tener como objetivo abarcar dentro de una ley orgánica todas las manifestaciones de capacidad contributiva susceptibles de ser consideradas como hechos imponibles $y$ darles el tratamiento impositivo adecuado en relación al beneficio real $o$ presunto que originan y la situación personal del contribuyente. Dentro de los hechos imponibles debe estar contemplado el derecho de propiedad en sí y las ganancias de capital en transferencia de predios.

3. Las diversas tarifas de este Impuesto a la Propiedad Predial deben armonía con sus fines fiscales y extrafiscales, pero dentro de los límites de una presión tributaria que económica y psicológicamente no desaliente la inversión. Asimismo, las tarifas deben permanecer invariables por un período de 20 años. Ello deberá garantizarse debidamente y actuará como aliciente en favor de esta actividad. Esta inamovilidad de uno de los factores que intervienen para fijar la cuantía del tributo se justifica, pues el otro elemento que participa en unos casos es el valor de los predios o el valor de operaciones relacionadas con su transferencia o el monto de la renta y ganancia de capital que produzca su explotación o venta. Es decir, que se trata de un elemento en constante aumento, lo que asegura suficientemente el incremento automático del rendimiento fiscal.

Dentro de esta idea, las transferencias de inmuebles deben estar gravadas con distintas tarifas, según los valores de las propiedades. Así se favorecerá el comercio de bienes de las clases con menos recursos. 
Las tasas por prestación de servicios deben ser iguales y estar estructuradas de conformidad con el costo real de los mismos. Ello se justifica en el alumbrado y baja policía, porque deben ser de la misma calidad en todo el vecindario. Igual temperamento debe regir respecto de los arbitrios de parques y jardines.

Las tarifas que gravan la renta proveniente del lucro en compraventa de inmuebles deben ser mayores que las correspondientes a las ganancias de capital. Las tarifas previstas para las rentas presuntas deben ser menores que las que afecten a la renta real. Las rentas reales deben ser gravadas en mayor proporción que las presuntas, pues en ese caso hay una realización de riqueza y en el otro sólo un consumo, lo que no tiene la misma significación o medida de capacidad tributaria. En igual forma, las ganancias de capital que provienen de la transferencia eventual o esporádica de inversiones deben ser afectadas en menor proporción. Ello se justifica en su condición de riqueza que interesa al ahorro y cuya detracción no debe menoscabarse en su condición de fuente de renta futura.

Las tarifas aplicables al derecho de propiedad de tierras rústicas improductivas debe ser mayor que las aplicables a las tierras cultivadas. Más aún, puede pensarse en tasas progresivas que respondan a un propósito de incentivar la reforma agraria.

La tarifa de los predios industriales deben ser menores a las de casas-habitación y predios rústicos. En este aspecto, la diferenciación se justifica por la mayor incidencia que tiene el impuesto en su aspecto de traslación en los dos últimos casos.

4. Para fijar las distintas materias líquidas gravables según los diferentes hechos imponibles, deben contemplarse, según corresponda, la deducción de egresos relacionados con la conservacićn del bien, los gastos necesarios para su rendimiento y los derivados de la situación personal del contribuyente.

De conformidad con lo expuesto, tanto en los casos de transferencia, como de afectación del derecho de propiedad en sí, debe contemplarse la deducción de gravámenes hipotecarios que afecten los predios involucrados. Por el contrario, cuando se trate de determinar los beneficios liquidos que tengan la condición de rentas reales o presuntas, debe contemplarse la deducción de intereses hipotecarios.

En materia de deducciones vigentes se consideran aceptables las existentes actualmente para el Impuesto a los Predios y el Impuesto a las Utilidades. En cambio resulta incomprensible que los propietarios de terrenos sin construir no tengan derecho a considerar determinados egresos como válidos para establecer el monto gravable con el tributo.

En ese mismo sentido, debe preverse la existencia de exenciones en la base en los casos de renta presunta o del Impuesto Territorial a los predios urbanos. Estas exenciones que representarán determinados valores, operarian en forma similar y adicional a las deducciones que por cargas de familia, a cargo del contribuyente, contemple nuestra ley tributaria vigente en la aplicación de los impuestos a la renta. Al respecto, es indudable que no puede afectarse en la misma forma a un contribuyente de familia numerosa que requiere de un inmueble mayor, que a un propietario persona individual que vive solo. Las necesidades son distintas $y$, por tanto, las capacidades tributarias son también distintas.

En igual forma, se trataría de abarcar el caso de predios que constituyen la única fuente de renta para personas incapacitadas de trabajar o jubiladas.

Ello sólo puede salvarse en parte mediante el sistema propuesto de exenciones en la base.

Finalmente, deberá contemplarse que en ningún caso el impuesto total anual a pagarse conforme al tributo unificado a la propiedad predial, exceda en su conjunto de un porcentaje aceptable de la renta líquida real o presunta que produzca el predio.

5. Que deben contemplarse únicamente excenciones que tengan su origen en la incapacidad contributiva del obligado al pago del tributo o, a razones de hecho, como por ejemplo en los casos del Fisco en que no puede ser acreedor y deudor simultáneamente de la deuda tributaria. Algunas excepciones pueden aceptarse por razones extrafiscales de carácter general. En ese aspecto tendriamos la enseñanza, el culto religioso o determinados servicios hospitalarios, cuarteles de bomberos y análogos. Otro tipo de exenciones fundadas únicamente en la persona no tienen justificación doctrinaria y serían anticonstitucionales. No debe olvidarse que la capacidad tributaria es la razón jurídica y económica principal del impuesto.

Fundadamente creemos que de operarse dentro de las condiciones propuestas se podrá obtener mayores ingresos fiscales sin distorsionar aún más nuestro régimen tributario y se habrá conseguido satisfacer los postulados básicos de orden fiscal y social. 